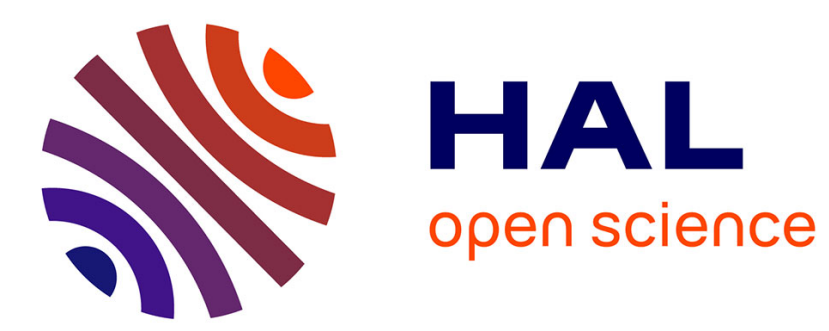

\title{
An afterthought on let alone
}

Bert Cappelle, Edwige Dugas, Vera Tobin

\section{To cite this version:}

Bert Cappelle, Edwige Dugas, Vera Tobin. An afterthought on let alone. Journal of Pragmatics, 2015, 80, pp.70-85. 10.1016/j.pragma.2015.02.005 . hal-01219314

\section{HAL Id: hal-01219314 https://hal.science/hal-01219314}

Submitted on 26 Oct 2015

HAL is a multi-disciplinary open access archive for the deposit and dissemination of scientific research documents, whether they are published or not. The documents may come from teaching and research institutions in France or abroad, or from public or private research centers.
L'archive ouverte pluridisciplinaire HAL, est destinée au dépôt et à la diffusion de documents scientifiques de niveau recherche, publiés ou non, émanant des établissements d'enseignement et de recherche français ou étrangers, des laboratoires publics ou privés. 


\section{An afterthought on let alone}

Bert Cappelle ${ }^{a}$, Edwige Dugas ${ }^{a}$ and Vera Tobin ${ }^{b}$

a University of Lille 3

Joint Research Unit UMR 8163 'Sciences, Texts, Language' (STL)

Université de Lille 3 - Bât. B

Domaine Universitaire du 'Pont de Bois'

Rue du Barreau

BP 60149

59653 Villeneuve d'Ascq Cedex

France

bert.cappelle@univ-lille3.fr

edwige.dugas@univ-lille3.fr

b Case Western Reserve University

Department of Cognitive Science

605 Crawford Hall

10900 Euclid Ave.

Cleveland, $\mathrm{OH} 44106-7063$

US

vera.tobin@case.edu

Corresponding author:

Bert Cappelle

tel. +32 50670402 (landline) or +32 470596869 (mobile)

Robrecht van Vlaanderenlaan 59

8200 Sint-Andries

Belgium 


\title{
An afterthought on let alone
}

\begin{abstract}
(max 200 words)
We here revisit the let alone construction, which was first described in a 1980s paper that put Construction Grammar on the map. Our focus is on a seemingly aberrant use where the first conjunct does not entail the restored second conjunct, as in / don't have ten children, let alone one. We argue that this use should not be considered as a highly exceptional speech error or as evidence that some speakers wrongly assume that the first proposition is the entailed one. First, a systematic examination of let alone examples extracted from the BNC and COCA shows that it is not exceedingly rare, as does a growing collection of authentic examples we have collected over the years. Second, it constitutes a usage type in its own right, whereby the first proposition has most contextual relevance and the second conjunct is represented by the speaker as an apophasis-like afterthought. There are transitional cases between the two types (canonical and afterthought), where both conjuncts have considerable relevance. For contemporary speakers, the afterthought use may require extraction of a general pattern with bleached semantics and pragmatics, possibly re-filled in with specific information.
\end{abstract}

\section{Keywords}

let alone construction, Construction Grammar, Gricean maxims, scalarity, apophasis

\section{Introduction}

\subsection{A classic construction}

In this paper we re-examine the let alone construction, first described in a landmark Language article by Fillmore, Kay and O'Connor (henceforth FKO) in 1988. This article, together with the chapter on there-constructions in Lakoff's book Women, Fire and Dangerous Things, which appeared just a year earlier (1987), is widely considered to be the foundational study of Construction Grammar. Though perhaps not so catchy as Goldberg's (1995) famous example sneeze the napkin off the table, which clearly shows that constructions may contribute meaning over and above what is contributed by the individual lexical items they host, let alone resonates with Construction Grammarians as a language phenomenon that lies at the basis of the paradigm they work in. 
For all its fame and familiarity, we argue here that the let alone construction has still not been given a fully adequate description. In particular, some speakers' use of let alone seems to deviate quite drastically from the way it is used in the example sentences in FKO's article and from its standard description in dictionaries. This seemingly aberrant use, which we will come to after first reminding readers of the grammatical properties characterizing the 'standard' use, raises interesting issues about the nature of pragmatic information encoded in constructions.

The brief but for now adequate definition in (1), taken from the Longman Dictionary of Contemporary English (LDOCE, s.v. let), along with its example sentence, can serve as a starting point to illustrate the main points that FKO made when they dealt with this construction:

(1) Let alone used after a negative statement to say that the next thing you mention is even more unlikely:

The baby can't even sit up yet, let alone walk!

The 'deviant' type superficially looks like an erroneous reversal of the parts making up a canonical let alone structure. An authentic example is shown in (1'):

(1') ... her muscles were so limp that most activities like walking, let alone sitting up, seemed like an impossible dream ...

(http://www.sutterhome.com/recipes/sutter-home-burgerbase-recipes/volcanoburger-with-molten-cheese-fresh-avocado-mash-and-a-0\#.U4baC_m1Yf5)[The boldface rendering of let alone in this and other examples in this paper is our own.]

\subsection{A deviant example?}

In a post on the linguistic weblog Language Log, Geoffrey Pullum (2013) discusses the contextualized example in (2):

(2) "No pictures should have been sent out, let alone been taken," said Trent Mays after he was found guilty of disseminating a nude photo of a minor, according to this account of the notorious Steubenville rape case.

Pullum comments: "If that is what Mays said, then he has apparently internalized the wrong meaning of the idiom let alone. He used it as if it had the inverse of its usual meaning. In other words, he apparently thinks that let alone means or even." Pullum further explains that on the generally agreed-on assumption that "distribution via social media of nude photos of a 
drunken naked 16-year-old girl being assaulted and raped should count as even more callous and heinous than merely taking the photos" (ibid.), it would have been coherent to say No pictures should have been taken, let alone sent out. Pullum then remarks: "The key thing about the meaning of let alone is that it has to connect a first half that is lower on some dimension to a second half that is higher on that dimension" (ibid.). The reader familiar with FKO's article will recognize the scalar semantics discussed there, and indeed, Pullum then goes on to refer to this classic account of the construction, which we will present in detail in Section 1.3. The background presupposition involves a scale of depravity. It allows one to infer that if an act low on that scale shouldn't have happened, then a fortiori any act higher on that scale shouldn't have happened either.

Two points are worth stressing. First, note that in rejecting this example, Pullum only refers to the meaning of the let alone construction, suggesting that speakers just get it wrong: "the difference between getting the relation the right way round and getting it reversed is what is of interest here" (ibid). Second, Pullum ends his post by marvelling at the complexity and subtlety of the canonical construction, which apparently speakers nevertheless manage to acquire. This leads him to conclude: "The wonder is not that Trent Mays got it wrong (...); the wonder is that any of us ever get it right" (ibid.).

Let us therefore examine two claims related to Pullum's post:

(i) Does an example such as (2) show that some speakers wrongly assume that let alone has as its meaning that the first proposition is entailed by the second rather than the other way round?

(ii) Is an example such as (2) really such an exceptional phenomenon? Do speakers as a rule use let alone only as described in FKO's article, such that (2) can be discarded as a very occasional performance error (or as one of the highly exceptional cases in which the normal acquisition of let alone has gone awry)?

In this paper, we will put the second claim to the test by means of a small-scale corpus study, complemented with a body of less systematically gathered but still substantial evidence (Section 2). For the corpus study (Section 2.1), we extracted a random sample of one hundred examples from the British National Corpus (BNC), using Mark Davies's search interface (Davies 2004-) and another hundred examples from the Corpus of Contemporary American English (COCA; Davies 2008-). In Section 3, we will look into the first claim above, by considering the reasons why someone would deviate from the canonical pattern and the linguistic mechanism that might allow such uses. First, though, we will discuss in some detail the canonical let alone construction as described in FKO (1988) and consider some 
refinements that have meanwhile been made in the literature. All of this information will be needed to show how the 'deviant' type differs from the canonical type.

\subsection{The canonical construction}

In FKO's treatment, let alone is analysed as the lexically pre-installed part of an otherwise variable template (i.e., a semi-schematic construction) that specifies rich information at the syntactic, semantic and pragmatic level. Let us deal with these levels in turn.

\subsubsection{The canonical construction's syntax}

Syntactically, let alone is argued by FKO to act as a coordinating conjunction, which just like and or or links constituents that have the same grammatical function. For example, in (1), sit up and walk both function as verbal complements to the auxiliary can't. Among other grammatical functions that can be linked in this way are Direct Object (e.g. The baby doesn't have the skill to sit up yet, let alone the ability to walk), Adjunct (not necessarily of the same syntactic category on either side of let alone, e.g. A baby can't even sit up at the age of three months, let alone when it's just two months old, where a prepositional phrase and a whenclause are conjoined) or Subject (e.g. A three-month old baby, let alone a two-month old one, can't sit up yet). In terms of word order, the speaker in principle has the choice of offering let alone and the second conjunct right after the first conjunct, as in the example just given, or postpone this material until the completion of a full clause (e.g. A three-month old baby can't sit up yet, let alone a two-month old one).

Another observation made by FKO is that the construction involves paired foci (i.e., informationally foregrounded constituents containing a prosodically stressed element): at least one focused element in the first conjunct is compared with and differs from at least one focused element in the second conjunct. FKO devote quite some attention to the possibility of finding multiple paired foci, of the sort used in the made-up example The baby can't even sit up when its parents help it, let alone walk when strangers just look on, which has three pairs of foci (1: sit up - walk, 2: its parents - strangers; 3: help it-just look on).

Further, the part following let alone is a sentence fragment whose correct interpretation can only be arrived at by adding elements that are explicitly present in the first part. Thus, walk in (1) has to be interpreted as the baby can't walk yet and not, say, as its parents can walk, so the propositional content of the second conjunct has to be 'restored' with elements from the first conjunct. 
Finally, let alone is a negative polarity item, occurring after what FKO, based on work by Klima (1964), call an 'affective trigger'. In (1), this trigger is straightforward syntactic negation marked on the auxiliary, but other well-described negative-polarity contexts are just as suitable to license let alone (e.g. I doubt the baby can even sit up yet, let alone walk, It's too soon for the baby to even sit up yet, let alone walk). Even in rare cases where let alone might occur after a purely positive clause (as in The baby can walk already, let alone sit up!, again made up here for ease of exposition), someone would have to have raised a contextual proposition (e.g. I heard the baby can't sit up yet) whose firm denial FKO suggest can serve as an appropriate affective trigger for the speaker.

\subsubsection{The canonical construction's semantics}

Semantically, the canonical let alone construction rests on a shared assumption that the propositions on either side of let alone can be seen as contrasted points on an implicational scale. Thus, in (1), the speaker draws upon the common knowledge that children first manage to sit up before they can walk, rather than the other way round. This assumption belongs to the speaker's and hearer's so-called 'common ground', i.e., a base of background information (assumed to be) taken for granted by the conversational participants (Grice, 1975; Stalnaker, 2002). The scalar nature of the construction prompts the hearer to consider the proposition that the baby can't walk yet (i.e., the proposition expressed by the syntactically 'restored' sentence fragment following let alone) as semantically entailed by the first proposition. If a baby can't sit up yet, then it's all the more obvious that it can't walk yet, as per the accepted ranking of babies' ability to walk and their ability to sit up on a scale of developmental chronology or ease of acquisition.

In some cases, the entailment follows from the lexica/properties of the focal items, which allow for a ranking on the well-known Horn scales (Horn, 1989; 2000) (e.g. He's not an assistant professor, let alone a full professor, They're not engaged, let alone married). However, as is emphasized by FKO and especially Kay (2004), the very use of a let alone construction may force the hearer to infer pragmatically that the focal items are ordered on a scale. This scale is then a so-called Hirschberg scale (Hirschberg, 1991), on which the focused constituents are not ordered by logicalentailment but by contextual entailment (cf. also Schwenter, 1999; Levinson, 2000). For instance, in cases where the hearer doesn't know much about babies and which skills come first in their development, (1) would have the effect of causing such a somewhat ignorant hearer to add this background information to the common ground (cf. FKO, 1988: fn. 6), a result of the process known as presupposition 
accommodation (Lewis, 1979; Von Fintel, 2008). So, if the hearer doesn't have mental access to the required scale, such a scale needs to be constructed. For an example in which lexical semantics plays an even smaller role, in order to interpret Jacob doesn't even sit up yet, let alone Sophia, the hearer can - in fact must - infer that baby Jacob is older than baby Sophia. Or if the context makes it clear that Jacob and Sophia are the same age, the only possible inference is that Sophia must be at some developmental disadvantage. In the words of Kay (2004: 681-682), such an example shows "the extent to which successful employment of scalar model constructions depends on the contextual inferencing abilities of the addressee". It is precisely this potential of let alone to create meaning not contributed by any explicit proposition in the utterance itself that one could argue provides a strong argument for Construction Grammar, which holds that the meaning of a complex unit may be more than the sum total of the component parts of that unit (Goldberg, 2006). For FKO (1988), however, it is the combination of syntactic, semantic, and also pragmatic properties that leads them to argue that let alone is a construction. So, let us finally turn to the pragmatics of let alone, as viewed by FKO.

\subsubsection{The canonical construction's pragmatics}

Pragmatically, the canonical let alone construction is argued by FKO to impose constraints on the distribution of informativeness and relevance across the two propositions. Given the context in which a let alone sentence is used, the first proposition gives more information than strictly requested, while the second proposition is more relevant to the conversation. For instance, (1) might typically be uttered in a context where someone just asked whether the baby can already walk. Such a previously posed proposition, whether asserted, questioned or merely hinted at, is what FKO call the 'context proposition'. The second part of the let alone construction then satisfies Grice's (1975) maxim of Relation ("Be relevant"), as it negatively responds to the context proposition while the first part satisfies Grice's first maxim of Quantity ("Make your contribution as informative as is required (for the current purposes of the exchange)" ) by not withholding an important fact, namely that the baby lacks an even more basic motoric skill, which in this context is more informative than the simple negation of the context proposition. The let alone construction thus simultaneously satisfies two Gricean maxims: in the first conjunct the maxim of Quantity and in the second conjunct the maxim of Relation.

The pragmatic effect of the let alone construction is that the proposition under discussion is more forcefully rejected by first negating a proposition that is related to it on an entailment 
scale. In a context where a proposition ' $p$ ' is raised and thereby gets our attention, the speaker first points out that 'not-q', where ' $q$ ' pertains to a situation that is more likely to actualize than ' $p$ ', so that by consequence and a fortiori 'not-p' can be asserted.

As is clear from this presentation, "[t]he lexical entry let alone thus implies an entire grammatical construction in which syntactic, semantic, and pragmatic information are interrelated" (FKO, 1988: 530). We will stress this interrelatedness again when we deal with a use of let alone that has hitherto not been given any attention in the literature. First, though, let us give a rapid overview of some of the ways in which FKO's description of let alone has been modified and complemented by other scholars, focussing on those refinements that are most relevant to our concerns.

\subsection{Post-FKO refinements}

Some scholars have taken issue with the status of let alone as a straightforward negative polarity item (NPI). For Sawada (2003), 'negativity' is not a property of the let alone construction, which he argues is characterized by the speech act function of "objection to the previous utterance" (p. 135). This account differs from that of FKO, who speak of "denial of the context sentence" (1988: 519). Sawada correctly distinguishes three types of environments for let alone: (i) explicit negative (e.g. The baby cannot even walk, let alone go shopping), (ii) implicit negative (e.g. You are too ill to get out of bed, let alone go shopping) and (iii) explicit positive (e.g. You've got enough material there for a whole semester, let alone a week). In defense of FKO, we would like to point out again that FKO did also consider the third type, though they did not go so far as to abandon the NPI status of let alone.

Toosarvandani (2008a) argues, in line with FKO, that let alone's lexical semantics makes reference to a scale (i.e., scalarity is inherent to it) but that the precise scale involved depends on the context. In addition, he suggests that the case of let alone lends support to the distinction introduced by Giannakidou (2007) between grammaticality-licensed NPIs (e.g. any) and pragmatically-licensed NPIs (e.g. let alone). For instance, while any cannot occur inside the scope of each (e.g. "Each student who saw anything spoke to the police), Toosarvandani (2008a) shows that this is possible for let alone, as in his quoted authentic example Each shot that is fired, let alone seen to hit its mark, in one zone is expected to bring victory across the whole front. Toosarvandani (2008) also agrees with FKO that there can, for some speakers at least, be positive occurrences of let alone (e.g. A. He was pleased. - B. He was delighted, let alone pleased (FKO: 519 fn. 13)), which he refers to as 
the 'high scalar' version of let alone, as opposed to the more common/frequent 'low scalar' version accepted by all speakers. In both cases, what is required is that the entire utterance containing let alone complies with the Gricean maxim of Quantity. Elsewhere, Toosarvandani (2009) shows that not just the second conjunct but also the first must be relevant to what he calls the 'question under discussion' and what has been called above, in FKO's terms, the 'context proposition'. We will come back to this point later on, in Section 3.1.

Janssen and Van der Leek (2010), like Toosarvandi (2008), present let alone as a polarity-sensitive item which is not necessarily an NPI, as it can function in both negative and positive environments. The authors lean heavily on the work of Fauconnier (1975, 1976, $1979)$ and Israel $(1996,1998)$ in claiming that "the grammar of polarity sensitivity is based not just on syntax or semantics, but crucially on pragmatic factors which determine what one may reasonably infer from the use in context of a given proposition; (Israel, 1996: 620, cited by Janssen and Van der Leek, 2010: 323). This is not fully in disagreement with FKO"s treatment of the let alone construction, which as we saw also provided room for contextual accommodation.

Janssen and Van der Leek (2010) do provide an original account for a double problem mentioned in FKO's article, namely that (i) in a sentence such as The baby can barely sit up, let alone walk, the word barely cannot be replaced by almost (compare: "The baby can almost sit up, let alone walk) and (ii) that such a sentence cannot be interpreted as "\#The baby barely sits up and therefore, a fortiori, the baby barely walks' but instead means 'The baby barely sits up and, therefore, a fortiori, the baby does not walk'. The puzzling fact about (i), according to FKO, is that we know what the sentence with almost would mean if it were grammatically acceptable: it would express that, since the baby cannot sit up, it certainly cannot walk either. The curious fact of the matter is that, although both almost and barely appear to have "limiting semantics" (FKO, 1988: 529), only the latter is syntactically a suitable negative polarity trigger. As for (ii), what bothers FKO is this: while "barely may be analyzed semantically as "almost not" (...) an explanation would still be required why only the not part of this complex operator distributes semantically to the second (...) conjunct" (FKO, 1988: 529). FKO acknowledge that "[they] are not at present able to offer such an explanation".

Janssen and Van der Leek's solution to this double puzzle is presented independently of that of Toosarvandani (2008b, 2010), which corresponds to theirs in its essence, if not in all of its terminological sophistication. Verhagen (1994), too, has offered an explanation along similar lines. We will focus here on Janssen and Van der Leek's proposal that FKO's problem can be solved by letting the let alone construction hinge no longer on representational concepts and truth-conditional logic but on a scalar operator's properties in terms of 
orientation, that is, whether it is scale-preserving or scale-reversing (cf. Horn, 1972; Israel, 1998). The difference boils down to the fact that almost allows entailment from top to bottom along a scale, while barely does the exact reverse. Given a scale of actions that are increasingly difficult to achieve, with the easiest actions at the bottom and the hardest at the top, if you can almost do $Z$, it can be inferred that you can do any action $X$ and $Y$, where $X$ and $Y$ are lower on the scale. By contrast, if you can barely do $X$, it can be inferred that you cannot do any action $Y$ and $Z$, where $Y$ and $Z$ are higher on the scale. Hence, what matters for the acceptability of such scalar operators is from which perspective they approach a scale, as it were: "almost and barely have, as part of their intrinsically scalar meaning, a positive and negative orientation respectively" (Janssen and van der Leek, 2010: 329). ${ }^{1}$ This is why almost is possible with let alone in positive polarity contexts, as is shown by FKO (1988, fn. 15) themselves (e.g. Can the baby sit up yet? - The baby can almost walk already, let alone sit up!. ${ }^{2}$ Such contexts are scale preserving (i.e., they support inferences from higher to lower values on a scale). As for the impossibility of carrying the 'almost' part of the semantics of barely over to the second conjunct, this problem only arises, according to Janssen and Van der Leek (2010), if the semantics of a let alone construction is a rigid schema where all the propositional content of the first conjunct is 'copied' to the second conjunct (except of course for the focused elements, which have to differ). Janssen and Van der Leek accord more importance to common-sense reasoning than FKO. Since barely suggests that a value was reached but only just so, it would be nonsensical to say for any higher value that it was also reached but only just so. The only sensible interpretation is that any sufficiently higher value was not reached - period. This interpretation does not follow from a representational schema but from pragmatic reasoning that is external to what has to be coded as part of the construction's information. Just how much semantic and pragmatic information needs to be associated with the let alone construction is, indeed, a question that we will further explore in the remainder of our paper. We must first establish how exceptional

${ }^{1}$ Horn (2002: 1) speaks of "mirror-image approximative adverbs". He provides the following contrast:

(i) a. Gore almost won the election. $\rightarrow$ a.' Gore didn't win the election.

b. Bush barely won the election. $\rightarrow$ b.' Bush won the election.

As Horn then points out, "almost is in part semantically negative - from (1a) it follows that (1a'), while barely is correspondingly in part positive - from (1b) we conclude that (1b') is true."

${ }^{2}$ Or for an authentic example:

(i) During the War we had almost a monopoly, let alone the leadership, in tank warfare ... (www.churchill-society-london.org.uk/Locusts.html) 
the presumed deviant type really is. This is an empirical question that can be answered with the help of corpus data, as we will show in Section 2. The specific properties of this type will then be discussed in Section 3.

\section{Results}

\subsection{Corpus examination}

Among our set of 200 randomly selected examples from the BNC and COCA, we found nine examples that could be argued to be similar to (2), in that they fail to display an obvious entailment relation from the first conjunct to the (restored) second. This means that 4.5 per cent of utterances with let alone may be of the 'deviant' type. Below, we present some clear cases and provide some comment between brackets:

(3) I had no idea that a physician could do something like that, especially to his own child, let alone to anyone else's child. (COCA, 1992, SPOK, Ind_Geraldo) [Here, the speaker accuses a physician, who impregnated her, of inducing labour and then killing the baby after it was successfully delivered. One could argue that killing one's own child is even more atrocious, ruthless and incomprehensible than killing anyone else's; let alone can be replaced here by or for that matter.]

(4) Clearly an editor who knew his typography but one who never spotted that the publication was no longer being pasted together by hand - let alone produced at a mere 600 dots per inch. (BNC, G00, W_Commerce)

[The (ex-)editor in question had observed a change in the font type of a magazine that he had previously edited. What he had not noticed was that the magazine was no longer manually typeset and he even failed to see that it was printed by a new type of low-cost printer that was merely capable of $600 \mathrm{DPl}$, the resolution reached by a decent inkjet printer or a lower-range laser printer only. Relatively poor print quality is arguably easier to spot than the shift to electronic typesetting.]

(5) Yet Nazism was not cited as the sole, let alone the chief, danger to the Catholic Church. (COCA, 1999, ACAD, Church\&State) [If Nazism was not the sole danger to the Catholic Church, it could still be the chief danger; let alone can be replaced by or even.] 
If we wanted to turn the above examples into instances of the canonical let alone construction, we would have to reverse the order of the conjuncts. ${ }^{3}$ For instance, in the last example, it would be more coherent to say that Nazism was not cited as the chief, let alone the sole, danger to the Catholic Church, at least if the intended meaning was that Nazism was not considered the main threat, and that therefore, a fortiori, it was not considered the only threat to the Church of Rome. (We will argue below, however, that this is not the intended meaning.)

In fact, for some of the examples we identified, one could doubt whether they involve any scalar ranking of the propositions at all. That is, they cannot be claimed to have a wrong, reversed or 'illogical' ordering, as there is no obvious entailment of the proposition in either direction:

(6) She can't seem to remember a thing anymore. The day or the hour, let alone the year. (COCA, 1991, FIC, KansasQ)

[Remembering the year is, if anything, more likely than remembering the day or the hour, but a scalar relation in whatever direction may not have been presupposed at all.]

(7) Let's stop trying to get women to support us by crawling to them - it's obvious they prefer voting for devils or weeds than for decent men (let alone decent women), and bribing them with a Ministry didn't work. (BNC, 1, CAJ, W_non_ac_polit_law_edu) [Just because women don't seem to vote for decent men doesn't mean they would not vote for decent women if given that choice. Conversely, if women don't vote for decent women, this does not preclude them from voting for decent men. There is no entailment in either direction.]

We present all further corpus examples in the Appendix. All in all, in 200 randomly retrieved corpus examples from the BNC and COCA, four to six examples come across as 'illogical', at least if one assumes the only correct use of let alone is as described by FKO. So, even if we do not count examples like the ones in (6) and (7), at least 2-3\% of sentences with let alone are like the one discussed by Pullum; they seem to have an entailment which is the reverse of that associated with the 'canonical' let alone. And if we include the cases for which it is

\footnotetext{
${ }^{3} \mathrm{~A}$ mere reversal of the conjuncts is not always sufficient. For instance, a reversal of (3) would also require changing anyone else's child to a child and dropping especially.l had no idea that a physician could do something like that to a child, let alone his own child.
} 
hard to decide which of the two situations can reasonably be considered the more likely, we can conclude that $4.5 \%$ of let alone sentences, or almost one in every twenty, is of the 'deviant' type. This may not seem that much, but we hope to have shown that such examples are common enough that we should not automatically reject them as exceptional performance errors.

\subsection{Further evidence}

In addition to the examples that appeared in the above random sample of corpus data, we also have a collection of more than two dozen such sentences, from various sources, which deviate from the 'canonical' use as described in the classic study by FKO or any of the subsequent studies. Many involve unambiguous scalar structure, in an unambiguously noncanonical order. Below are just five examples. A list of twenty similar additional examples is provided in the Appendix.

(8) "Where's the father of your ten children?"

Chelsea looked at me from over her book, "First, we don't have ten children, let alone one, and second, he's outside smoking his life away."

(http://www.mibba.com/Stories/Read/147313/In-Your-Eyes-I-Lost-My-Place/1/)

(9) He's won five times this year on Tour, which is not just good but remarkable. Very few golfers have won that many events in one year, let alone their careers. (http://sports.yahoo.com/news/golf--tiger-woods-sputters-toward-another-yearwithout-a-major-204301330.html)

(10) My Grandmother has Alzheimer's and doesn't remember me at all, let alone who she is.

(http://www.reddit.com/r/pics/comments/15excv/my_grandmother_has_alzheimers_a nd_doesnt_remember/)

(11) The odds of being attacked, let alone even just seeing a shark are so small! (http://www.perthnow.com.au/news/swimmer-loses-legs-in-south-african-sharkattack/story-e6frg12c-1226151045467)

(12) Boyfriend? She'd never had one, let alone, for that matter, wanted one. (https://www.fanfiction.net/s/2556576/3/Just-a-Girl) 
Note the use of even just and for that matter in (11) and (12), which indicate quite clearly that these examples are of a different type than the canonical one (compare Can the baby walk yet? - The baby can't crawl yet, let alone (\#even just / \#for that matter\} walk). All of the examples above, together with those given in Section 2.1 and the ones provided in the Appendix, suggest that we are dealing here with a usage type of let alone in its own right. They are too common for each of them individually to be considered as a one-off lapse or as a case of speaker idiosyncrasy.

In answer to the second question raised in Section 1.2, we can now confidently state that the example in (2) is not extremely exceptional, let alone unique. We still need to consider the possibility that some speakers (perhaps even a sizeable number of them) have internalized, as Pullum (2013) suggests, "the wrong meaning" of let alone. This issue, which requires more detailed qualitative analysis than quantitative data, is taken up in our next section.

\section{Discussion}

In an online reaction to one of the sentences given in the Appendix, a commentator wrote, "Swap those clauses fool!" But our point is that speakers who utter sentences of the type discussed here know exactly what they do. Some of them are highly proficient writers, such as professor of psychology Dan Ariely, who produced Appendix sentence (23) in his bestselling book Predictably Irrational. Our contention is that if these speakers and writers were told to reverse the order of the clauses, many would object by saying that the result is not what they had in mind and that the sentence as produced felt just right in the context, despite the lack of any 'logic' between clauses. In other words, we need to take that context into account in order to fully grasp the properties of this 'discrepant' type.

\subsection{The relevance of the first conjunction}

According to FKO, the let alone construction allows speakers to navigate the complex demands posed by the previous discourse: it allows them to simultaneously satisfy Grice's maxim of Relation (by settling the context proposition at issue in the second conjunct) and respect Grice's (first) maxim of Quantity (by stating something in the first conjunct which is more informative than the verdict about the context proposition). For instance, imagine the following exchange: 
(13) Speaker A: My aunty Mary had a tough time raising her ten children. So, how do you cope?

Speaker B: You're asking the wrong person. I don't have any children, let alone ten.

In this example, speaker $B$ rejects a proposition that speaker A willingly or unwillingly introduces in the discourse, namely that speaker B, just like speaker A's aunty Mary, has lots of children. To be more precise, speaker B imputes to speaker $A$ the implicature that speaker $B$ has as many as ten children. The second conjunct is relevant with respect to this proposition - it denies it - while the first conjunct says something more informative: 'I don't have any children'. That this is indeed more informative follows from the possibility that not having ten children does not preclude the possibility of having nine, eight or seven children, which would still be very many in light of what is considered normal. Holding back the information that one has no children at all would be a violation of the maxim of Quantity if speaker A labours under the assumption that her interlocutor has many children.

Given the scale of natural numbers, not having any child - that is, not even one - logically entails not having ten children. As a consequence, speaker B could just as well have said, "You're asking the wrong person. I don't have any children". That B doesn't have a higher number of children than zero, possibly even ten, would then have been inferable. In light of this entailment relation that is part of the semantics of the canonical type that an example such as (8) - we don't have ten children, let alone one - can be said to be illogical: if one doesn't have ten children, it cannot be inferred that one doesn't have any children. Indeed, one could then have zero children, but possibly also one child, two children, etc. all the way up to nine - and in fact, one could even have eleven or more children.

Yet, while it is true that there doesn't seem to be any logic in (8), it is not fully incoherent. The first conjunct could be analysed as a stand-alone utterance which is at the same time (highly) relevant and (somewhat) informative. It is relevant because it denies a proposition present in the context: Where's the father of your ten children? presupposes that the interlocutor has ten children. And it is also informative, as it states that something which the interlocutor believes or suggests to be the case is not true. But, as we just pointed out, saying that one does not have ten children if one doesn't have any child is far from maximally informative. The speaker may therefore add this information explicitly, to comply with the first maxim of Quantity. Let alone one here sounds as if it is added by the speaker only after she realizes that her denial of an echoic proposition (namely us having ten children) fails to satisfy the maxim of Quantity. 
What we propose here is that an example such as (8) is not discrepant in providing the proposition expressed in the first conjunct - We don't have ten children - as entailed by what the reconstructed second conjunct conveys - We don't even have one child. If such an entailment were intended, then the speaker could just as well have uttered We don't have ten children, since/because we don't have even one child. Clearly, the speaker is not concerned with representing the first proposition as entailed by the second. Rather, (8) is deviant compared to the canonical type in terms of its pragmatics: it represents the first proposition as relevant right away and then represents the proposition following let alone as even more informative than the first.

As a further argument to show the speaker uttering an example such as (8) does not do this as a result of confusing the entailment direction, as Pullum (2013) suggests, consider (14), an exchange in a conversation where people ask about each other and in which speaker A didn't mention anyone having ten children:

(14) Speaker A: So, do you have any children?

Speaker B: \#No, we don't have ten children, let alone even one.

Even those who do not like a sentence such as (8) would probably agree that the acceptability of a sentence such as (14) is considerably reduced in comparison. This is not because its semantics is different - it isn't - but because the pragmatics of this example is incoherent: the first proposition is no longer relevant given the context.

We can now answer the first question we raised in Section 1.2: the example discussed by Pullum (2013), given in (2), and similar examples above, are not merely a matter of some speakers wrongly assuming that in $\mathrm{X}$ let alone $\mathrm{Y}$, it is $\mathrm{X}$ that is entailed by $\mathrm{Y}$. More to the point, these examples show that at least for some speakers, let alone can be used to introduce an afterthought after the expression of a proposition that has more contextual relevance than this afterthought. Let alone, though now an idiom, may originally (cf. footnote 3 below) have been felt to mean something like 'let untouched (as a conversational topic)' hence the lower contextual relevance of the second conjunct. For some speakers, this sense may still be accessible. This would explain why let alone... can be deployed as a rhetorical device known as an apophasis, in which the speaker somewhat paradoxically brings something up by denying that it should be brought up at all, just like not to mention... and similar expressions attested cross-linguistically (e.g. French sans (même) parler de... 'without (even) talking about...' or German geschweige (denn)..., 'to be (then) silent 
about...'). ${ }^{4}$ Thus, when let alone is used to introduce an afterthought, the speaker aims to say: 'l've already made a strong statement, and l'm not even yet counting or considering the following notable fact or point, which I decide not to go into but which could be added to reinforce what I just said'.

\subsection{Bridging cases}

We have rejected the possible objection that examples (2) to (12) - the 'deviant' type - are simply incorrect or accidental, while acknowledging, of course, that they are not as frequently used as the canonical type. By stressing that this special use has its own raison d'être, it now looks as if we are dealing with two rather distinct let alone uses, especially insofar as the divergent properties of the two uses are encoded as grammatical information that speakers know in order to use each of them correctly. But do the canonical type discussed by FKO and others (cf. Sections 1.3 and 1.4) and the deviant type discussed in this article really constitute two radically different uses of the lexical entry let alone? If so, this may still give some ammunition for the view that some speakers have internalized a wrong version of the let alone construction (i.e., a version with the wrong pragmatics) ${ }^{5}$

In actual fact, the two uses are not that distinct. That is, there may be cases that can be interpreted either way, blurring the distinction. Toosarvandani (2009) discusses the following interesting example (underlining ours):

${ }^{4}$ Note that the connective not to mention allows uses similar not only to afterthought let alone (cf. (ia)) but also to canonical let alone (cf. (ib)):

(i) a. I haven't been to the gym consistently in months, not to mention even stepped foot in my gym in over a month now, so I feel pretty outta practice.

(http://www.12ozprophet.com/forum/showpost.php?p=8766611\&postcount=3353)

b. ... and there are a lot of people who cannot even get out of bed and walk, not to mention run at the Olympics (http://www.dnaindia.com/sport/report-usain-bolt-can-toy-with-youshawn-crawford-1386915)

It may be the case that speakers use let alone with the same diversity of functions as they know is possible for what seems to be a functionally close item such as not to mention.

${ }^{5}$ On a terminological note, we will keep adopting in this section the pre-theoretical terms uses or types rather than constructions. In our next section, we willtreat the two types as constructions, in the Construction Grammar sense. 
(15) Several commentators have claimed that on this expedition Gould's party was the first ever to reach the great western bend of the Murray overland from Adelaide. But we cannot be certain that Gould even got as far as the river at all. He himself says he 'spent five weeks entirely in the bush in the interior, partly on the ranges and partly on the belts of the Murray.' Although he had a magnificent view from the top of the Mount Lofty range of the Murray River, winding its course across the flats through a belt of dense dwarf eucalypti, there is no mention of his ever having reached its banks, let alone the remote western bend 100 miles away.

In terms of scalar properties, the let alone sentence used here is of the canonical type: if Gould's expedition team didn't even reach the banks of the Murray river, then this entails that they can't have reached the more remote western bend (under the assumption that they would follow the river to reach this destination). The let alone sentence also displays the pragmatic properties of the canonical type as described by FKO: the context raises the question whether Gould really reached the western bend of the river (single-underlined), and the second conjunct negatively answers that question, while the first part states something which is considered of more informative value, namely that Gould's team probably didn't even reach the river. Yet, as Toosarvandani points out, the first conjunct of the let alone sentence also corresponds to the question that is most immediately under discussion, namely whether or not Gould reached the Murray river (double-underlined). In this respect, this let alone sentence is not unlike the deviant type, in that the first conjunct has most contextual relevance, with respect to the topic that is most active at its utterance.

Considering this active topic (i.e., Did Gould reach the Murray river?), the remainder of the sentence (let alone...) has the flavour of an afterthought, even though it picks up a propositional topic raised earlier in the context. This example therefore shows that the canonical use and the afterthought use of let alone are not that distinct.

For another bridging case, consider the following example taken from a news article that deals with a court case in which two young football players are sentenced for sexually abusing an intoxicated 16 -year-old girl:

(16) Throughout this trial, the two defendants and a parade of friends who wound up mostly testifying against the defendants, expressed little understanding of rape - let alone common decency or respect for women. (http://sports.yahoo.com/news/highschool--steubenville-high-school-football-playersfound-guilty-of-raping-16-year-old-girl-164129528.html) 
As in (15), the scalar structure of this let alone sentence seems to follow the canonical type: if you struggle to understand that taking sexual advantage of a non-moving girl counts as rape, then it's even less likely that you express (just) common decency or respect for women. Yet, unlike in the canonical let alone type but again as in (15), it is the first conjunct that may have most contextual relevance, given that the article is first and foremost about a rape case in court. The typography also presents the let alone part as additional information that was not planned at the onset of the utterance. It does have contextual relevance, though, because the article is also about a kind of teenage culture in which male youths feel entitled to exert power and control over girls. In that respect, the contextual relevance is spread over the two conjuncts. Thus this example has again key properties of both the canonical and the afterthought type.

It is not inconceivable that such transitional cases may help one type to develop from the other, for those language users that make use of the afterthought type. ${ }^{6}$ In the next section, we will argue that the two uses may be linked by an abstract let alone construction that generalizes over some of their more specific properties.

${ }^{6}$ Synchronically, it is most plausible to consider the afterthought use as an extension of the canonical use, given that the latter is much more frequent and that the former is not considered correct by some language commentators (which suggests that not allspeakers of English extend the canonical type this way). Diachronically, however, there are reasons to assume that it is actually the afterthought use that originally provided the basis for an extension to what is now the canonical type. First, note that the oldest examples of let alone attested by the OED, from the early nineteenth century, are of the afterthought type. For example:

(i) 1812 M. Edgeworth Absentee xiii, in Tales Fashionable Life VI. 269, I didn't hide, nor wouldn't from any man living, let alone any woman.

(ii) 1843 F. A. Kemble Rec. Later Life III. 33 Going out of town is very agreeable to me on my own account, letting alone my rejoicing for my children.

Secondly, its spatial etymology suggests that let alone draws on a conceptual metaphor (cf. Lakoff and Johnson, 1980) whereby a topic is a location or a building: you can approach a topic, go into it, look at it from several angles, explore it or, rather, leave it behind you, stay away from it or pass by it. The afterthought use of let alone, where the speaker merely mentions a topic without going into it, is in line with these latter metaphorical expressions. This likely spatial metaphorical basis is shared, furthermore, by the Dutch expressions nog daargelaten (lit. 'still (having been) left there') and laat staan (lit. 'let stand'). Nog daargelaten... is used as a classic apophasis ('Quite apart from the fact that...') and while laat staan is used much like canonical let alone, afterthought uses can occasionally be found for this itemas well (Cappelle, 2013). 


\subsection{Generalization of pragmatic information}

On the basis of FKO's article, it is possible to represent the canonical let alone construction as follows, simplifying the syntactic part:

Canonical let alone construction

Syntax: $\quad \mathrm{X}_{\text {clause }}$ let alone $\mathrm{Y}_{\text {clause fragment }}$

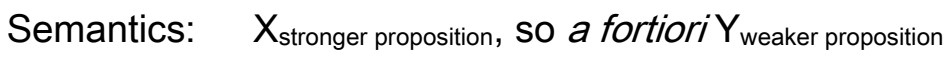

Pragmatics: $\mathrm{X}$ is moreinformative, $\mathrm{Y}$ is morerelevant

Let's assume that this is the most prototypical construction and that the 'illogical' afterthought construction, represented schematically below, is more peripheral. (By 'illogical' uses, we have in mind only cases like the one rejected by Pullum (2013), which seem to reverse the entailment relation. As we have seen, not all afterthought uses involve any entailment, reversed or otherwise - see again examples (6) and (7)).

'illogical' afterthought let alone construction

Syntax: $\quad \mathrm{X}_{\text {Clause }} /$ et alone $\mathrm{Y}_{\text {Clause fragment }}$

Semantics: $\quad X_{\text {weaker proposition, } \text { and }} Y_{\text {stronger proposition }}$

Pragmatics: $\mathrm{X}$ is morerelevant, $\mathrm{Y}$ is moreinformative

Note that the semantics here does not represent that $X$ can be stated all the more forcefully (a fortiori) given $\mathrm{Y}$; it just says that the construction makes two statements, and that the first is weaker than the second. But how is it possible for the pragmatic part and (an important aspect of) the semantic part of the afterthought construction to be flipped-around versions of the corresponding parts in the canonical construction? In the preceding section, we saw that there are bridging cases, where both $X$ and $Y$ have relevance. In addition, speakers may generalize over the semantic and pragmatic information of the canonical let alone construction. To see how this can be the case, we first have to realize that the pragmatic information of this construction is even much richer than FKO make it out to be. It possibly contains all of the information in the following extended version:

Canonical let alone construction (with more explicit pragmatics)

Syntax: $\quad \mathrm{X}_{\text {clause }}$ let alone $\mathrm{Y}_{\text {clause fragment }}$

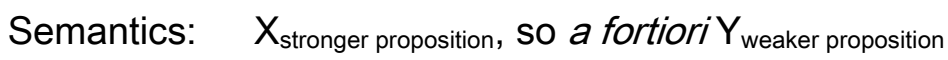

Pragmatics: $X$ is more informative, $Y$ is more relevant

$X$ could suffice on its own in the context, so it's not necessary to state $Y$ The speaker portrays $Y$ as not worthy of much attention

Let's take an authentic corpus example to make this more concrete: 
(17) Dear Guitarist I am in a band and we are still at school. We have a problem that a lot of youngsters such as ourselves can relate to. It is concerning PAs and speakers: they just cost too much. To buy a brand new PA system costs a lot of money for a single person, and as a group it is a huge risk as we are still at school (lower 6th) and do not wish to spend that sort of money when we cannot guarantee we will still be together in a week, let alone a year's time. (BNC, 1, C9J, W_pop_lore)

In this example, we cannot guarantee we will still be together in a week is syntactically a clause, and a year's time is a clause fragment, which can be restored as we cannot guarantee we will still be together in a year's time. The former proposition is stronger: that you aren't able to say whether a week from now you will still be together as a band is a statement that grabs the reader's attention more than that you can't be sure whether the band will still exist in its present form in a year's time. The latter statement can therefore be stated all the more forcefully given the former. Turning to the pragmatic part of the sentence, the context did not mention a week as a time span, so the first proposition has little direct relevance to the context. By contrast, the context did more or less mention the notion of a year, via lower 6th and (a little more indirectly) via youngsters such as ourselves, so the second proposition has contextual relevance. The first proposition, being the stronger statement, is clearly more informative than the second. It could be used without the second proposition, which could be inferred anyway. And the speaker also suggests: whether or not we will still be together as a band in a year's time is something I don't even want to think about much. In other words, the speaker portrays the element mentioned in the second proposition as something that shouldn't be considered for discussion. ${ }^{7}$

${ }^{7}$ For Verhagen (1994: 279), the discourse-pragmatic function of laat staan (which is the Dutch equivalent of let alone) is "to direct the reader/hearer explicitly to the idea that the contents of the second conjunct are not relevant" (our translation). He argues that laat staan, being an imperative in form meaning 'let stand' (cf. footnote 6), incites the hearer or reader to think of the topic mentioned in this conjunct as something which can or should be dropped. This suggestion may then be taken advantage of by the writer/speaker, who may go on to contradict the second topic's irrelevance, as shown by Verhagen (1994). Two examples of this discursive practice are provided here for let alone; both coming from the beginning of an article (italics added for clarity in the second example):

(ii) I seldom spend 100 hours on anything these days, let alone a video game, but I spent at least that much time with Dragon Age: Inquisition, the latest sprawling epic RPG from BioWare studio that brought us Star Wars: Knights of the Old Republic and the Mass Effect series. Dragon Age: Inquisition is the third game in its fantasy franchise, (...) (techcrunch.com/2014/12/01/dragon-age-inquisition-review/) 
These extra aspects of pragmatic information may be retained in a more general, underspecified let alone construction, where the let alone $Y$ part already potentially has the status of just an afterthought:

Underspecified let alone construction

Syntax: $\quad \mathrm{X}_{\text {clause }}$ let alone $\mathrm{Y}_{\text {clause fragment }}$

Semantics: $\quad X_{\text {proposition, and }} Y_{\text {proposition }}$

Pragmatics: $X$ could suffice on its own in the context, so it's not necessary to state $Y$ The speaker portrays $Y$ as not worthy of much attention

Note that in this generalized construction, the semantics is bleached and the pragmatic information does not include the Gricean constraints, something we could call 'pragmatic bleaching'. ${ }^{8}$ This construction may be what is made use of in the case of (6) and (7) above, where neither of the two propositions seems stronger than the other.

The underspecified construction now allows for re-specification. First, if the speaker doesn't consider $Y$ worthy of much attention, this may be because it lacks sufficient contextual relevance. This opens the way for a reversal of the Gricean constraints. If it is the first proposition that is the most relevant one, then the second should at least have more informativeness - otherwise, the speaker shouldn't utter it at all. Note that in this respect, sentences with afterthought let alone exhibit the properties of sentences with typical information structure, since information generally flows from old to new. This, in turn, can lead to re-enriching the semantic information: the (second) more informative conjunct must express the stronger proposition (e.g., in (8), not having one child is a stronger statement than not having ten children, which is not that remarkable anyway; in (10), that your

(i) With its vast metal and glass structures forming a rampart around Abu Dhabi's swathes of luxury hotels, the sweeping opulence of the emirate's inner city is the last place you would expect to find a grain of sand, let alone a camel to ride. But drive two hours south towards the Saudi Arabian border, and you're worlds away from the rushed pace of urban life. This is the country's Empty Quarter, a seemingly boundless expanse of rolling, untouched dunes stretching all the way to Yemen. (...) Ah, the humble camel; riding one is a staple part of the Middle East holiday experience, and the animals are widely revered by Arabs. (...)

(http://www.telegraph.co.uk/travel/destinations/middleeast/11148651/Abu-Dhabis-most-thrillingdays-out.html)

${ }^{8}$ We use 'bleaching' here in the sense of a weakening or reduction of constraints (i.e., of information associated with a construction), but do not wish to associate this process with the process of grammaticalization (Heine, Claudi and Hünnemeyer, 1991; Hopper and Traugott, 2003). 
grandmother doesn't remember who she is herself is a more remarkable statement than that she doesn't remember you, etc.).

In'illogical' afterthought let alone sentences, let alone can be argued to function as a scalar implicature cancelling operator, an idea suggested to us by one of the reviewers. This seems correct. Just like in fact or evencancel the implicature 'not all' triggered by some in sentences such as Some, in fact all of them, came or Some and even all of them came, so we find that let alone may serve to signal that an implicature raised by the first conjunct is about to be countered in the second conjunct. To use our familiar example again, if the speaker says, "we don't have ten children", this could evoke in the mind of the hearer the idea that the speaker does have one child and possibly even quite a few (butnot ten). The purpose of the continuation "let alone one" is to cancel this implicature. As pointed out by Levinson (2000:81), "because [conversational] implicatures, unlike entailments, are defeasible, it is possible to assert the contrary, or explicitly raise its possibility, without any sense of contradiction".

The 'illogical' afterthought let alone construction thus has the following properties:

'illogical' afterthought let alone construction (with more explicit pragmatics)

Syntax: $\quad \mathrm{X}_{\text {clause }}$ let alone $\mathrm{Y}_{\text {clause fragment }}$

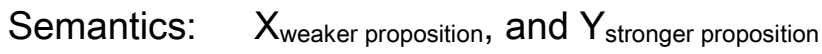

Pragmatics: $\mathrm{X}$ is more relevant, $\mathrm{Y}$ is moreinformative

$X$ could suffice on its own in the context, so it's not necessary to state $Y$

The speaker portrays $Y$ as not worthy of much attention

The speaker states $Y$ to cancel a conversational implicaturetriggered by $\mathrm{X}$

We have now provided a constructional account of how the canonical and the afterthought use of let alone are linked via a more general pattern which specifies what is common between them.

\section{Conclusion}

In this paper, we have argued against the view that the famous let alone idiom can only be used to first make a strong statement which can then serve as a springboard to forcefully reject a statement that is weaker by some easily accessible scalar presupposition (e.g. The baby can't even sit up yet, let alone walk!). We have described in great detail what we consider a fully legitimate and fairly common alternative use of let alone, illustrated by a 
sentence such as / would love to capture one, let alone even just see one, to use one more web-attested example. In this use, let alone introduces an afterthought about something that the speaker on the one hand wants to allude to, because it completes or reinforces the statement she just made, but on the other hand decides not to go into, as her statement without the afterthought was already a sufficiently relevant and informative one. This use is none other than an apophasis, the time-tested rhetorical trick of speaking of a subject by denying that it is your intention to bring it up. We formulated the hypothesis that, in the cases where the second proposition is stronger than the first one ('illogical' afterthought uses of let alone), the apophasis can be described as a scalar implicature cancelling operator.

Theafterthought use of let alone has been shown to be not extremely rare: it constitutes $4.5 \%$ of the cases in our sample of 200 corpus examples. For some contemporary speakers, the canonical use and the afterthought use may be cognitively linked via a more general constructional pattern with partially underspecified semantic and pragmatic information. Speakers who make use of afterthought uses of let alone may do so as a result of filling in certain details in this general pattern. It may also be the case that these speakers use let alone with the same diversity of functions as they know is possible for a functionally close item such as not to mention.

Not all afterthought uses have what looks like a 'reversed' order. This is because they do not require the propositions to enter in a scalar presupposition. Sometimes, the proposition added by way of afterthought is not stronger or weaker than the first proposition but just makes it more complete, as in the case of it's obvious [women] prefer voting for devils or weeds than for decent men (let alone decent women). Such uses may be produced directly by the general pattern.

The two uses (canonical and afterthought) differ pragmatically most crucially in the proposition that has the morecontextual relevance: it is the second in the canonical pattern; it is the first in the afterthought pattern. However, there are transitional cases, where both propositions have some contextual relevance, though they may not be relevant to the same aspects of the context. These cases seem to blur the distinction between the two types. The two types can be considered to be two related sub-constructions of the more underspecified general construction.

While some language users might find that speakers who produce an afterthought let alone sentence put things the wrong way round - namely in those cases where the first conjunct expresses a weaker proposition than the restored second conjunct - we are confident that these speakers meant to say just what they did. 


\section{Acknowledgements}

We would like to thank the following members of the Construction Grammar study group supported by the Maison Européenne des Sciences de l'Homme et de la Société (MESHS) at Lille: Dany Amiot, Maarten Lemmens, Cédric Patin, Fayssal Tayalati (all of these from the University of Lille 3) and Kristel Van Goethem (University of Louvain). We are also grateful to Chad Langford, Kathleen O'Connor and Christopher Piñon, three native English speakers working at the University of Lille 3, who took some time to discuss the afterthought use of let alone. By firmly rejecting this use as deviating from the norm, these linguists helped us to formulate our alternative analysis more clearly. Michael Israel (University of Maryland) aided in establishing the French-American connection among the authors of this article. We also benefited from comments made by William Croft (University of New Mexico), Laura Michaelis (University of Colorado at Boulder) and other members of the audience of a talk we gave about this special use of let alone at the $8^{\text {th }}$ International Construction Grammar Conference, held at the University of Osnabrück. Finally, we are grateful to the anonymous reviewers for their useful feedback on this article. All remaining inadequacies are, of course, ours.

\section{References}

Cappelle, Bert, 2013. Meer dan middelmatig [more than mediocre]. Over Taal 52 (2), 38-39. Fauconnier, Gilles, 1975. Pragmatic scales and logical structure. Linguistic Inquiry 6 (3), 353-375.

Fauconnier, Gilles, 1980 (1976). Etude de certains aspects logiques et grammaticaux de la quantification et de l'anaphore en français et en anglais [Study of certain logical and grammatical aspects of quantification and anaphora in French and English]. Doctoral dissertation, Université Paris 7.

Fauconnier, Gilles, 1979. Implication reversal in a natural language. In Guenther, F. and Schmidt, S. J. (Eds.), Formal Semantics and Pragmatics for Natural L anguage.Reidel, Dordrecht, pp. 289-301.

Fillmore, Charles J., Kay Paul,O'Connor, Mary Catherine, 1988. Regularity and idiomaticity in grammatical constructions: the case of let alone. Language 64 (3), 501-538.

Giannakidou, Anastasia, 2007. The landscape of EVEN. Natural Language and Linguistic Theory 25 (1), 39-81. 
Goldberg, Adele E., 1995. Constructions: a construction grammar approach to argument structure. University of Chicago Press, Chicago.

Goldberg, Adele E., 2006. Constructions at work: the nature of generalization in language. Oxford University Press, Oxford.

Grice, H. Paul, 1975. Logic and conversation. In Cole, P.,Morgan,J. L. (Eds.), Syntax and Semantics III: Speech Acts. Academic press,New York, pp. 41-58.

Heine, Bernd, Ulrike Claudi,Hünnemeyer, Friederike,1991. Grammaticalization: A conceptual framework. University of Chicago Press, Chicago.

Hirschberg, Julia, 1991. A Theory of Scalar Implicature. Garland,New York.

Hopper, Paul J,Traugott,Elizabeth C. 2003. Grammaticalization. Cambridge University Press, Cambridge.

Horn, Laurence, 1972. On the semantic properties of logical operators in English. Doctoral dissertation, University of California, Los Angeles.

Horn, Laurence, 1989. A Natural History of Negation. University of Chicago Press,Chicago.

Horn, Laurence, 2000. "Pick a theory (not just any theory): Indiscriminatives and the freechoice indefinite. In Horn,L. and Kato,Y. (Eds.), Negation and Polarity. Oxford University Press, Oxford, pp. 147-192.

Horn, Laurence, 2002. Assertoric inertia and pragmatic licensing. CLS 38 (2), 55-82.

Israel, Michael, 1996. Polarity sensitivity as lexical semantics. Linguistics and Philosophy 19, 619-666.

Israel, Michael, 1998. The rhetoric of grammar: scalar reasoning and polarity sensitivity. Doctoral dissertation, University of California, San Diego.

Janssen, Theo A.J.M, Van der Leek,Frederike, 2010. The let alone puzzle: a question of orientation. In Cappelle,B., Wada,N. (Eds.), Distinctions in English Grammar. Offered to Renaat Declerck. Kaitakusha, Tokyo, pp. 312-337.

Kay, Paul, 2004. Pragmatic aspects of grammatical constructions. In Horn,L., Ward, G. (Eds.), The Handbook of Pragmatics. Blackwell, Oxford, pp. 675-700.

Klima, Edward, 1964. Negation in English. In Fodor, Jerry A., Katz, Jerrold J. (Eds.), The Structure of Language. Prentice Hall, New York, pp. 246-323.

Lakoff, George, 1987. Women, Fire and Dangerous Things: What Categories Reveal about the Mind. University of Chicago Press, Chicago.

Lakoff, George, Johnson, Mark, 1980. Metaphors we Live by. University of Chicago Press, Chicago.

LDOCE. Mayor, Michael (Ed.), Longman Dictionary of Contemporary English. Fifth edition. Longman, Harlow: http://www.Idoceonline.com. 
Levinson, Stephen, 2000. Presumptive Meanings: The Theory of Generalized Conversational Implicature. The MIT Press, Cambridge, Mass.

Lewis, David, 1979. Scorekeeping in a language game. In Bauerle, R.,Egli, Urs, Von Stechow,Arnim (Eds.), Semantics from Different Points of View. Springer,Berlin, pp. 172-187.

OED. Oxford English Dictionary, 2nd edition, 1989. Online version, December 2013 update. http://www.oed.com/.

Pullum, Geoffrey K., 2013. X, let alone Y. Language Log, 5 April 2013. http://languagelog.Idc.upenn.edu/nll/?p=4553, accessed 2 February 2014.

Sawada, Osamu, 2003. Rethinking the let alone construction: what are its construction specific characteristics. Journal of Pan-Pacific Association of Applied Linguistics 7(1), 135-151.

Schwenter, Scott. A., 1999. Pragmatics of Conditional Marking: Implicature, Scalarity and Exclusivity. Garland,New York.

Stalnaker, Robert, 2002. "Common ground". Linguistics and philosophy 25 (5), 701-721.

Toosarvandani, Maziar, 2008. Letting negative polarity alone for let alone. In Tova Friedman and Satoshi Ito (eds.) Proceedings from Semantics and Linguistic Theory XVIII, 729746. Ithaca, New York: CLC Publications.

Toosarvandani, Maziar, 2008b. Scalar reasoning and the semantics of let alone.

Proceedings from the Annual Meeting of the Chicago Linguistics Society. 44(2), 51-64.

Toosarvandani, Maziar, 2009. The relevance of focus: The case of let alone reopened. In Biezma,María, Harri, Jesse (Eds.), UMOP 39: Papers in Pragmatics, GLSA, Amherst, Mass., pp. 105-123.

Toosarvandani, Maziar, 2010. Association with foci. Doctoral dissertation, University of California, Berkeley. people.ucsc.edu/ mtoosarv/papers/association-with-foci.pdf, accessed 16 November 2014.

Verhagen, Arie, 1994. Nauwelijks is niet bijna laat staan vrijwel helemaal [barely is not almost let alone nearly completely]. In Boogaart, Ronny,Noordegraaf, Jan (Eds.), Nauwe Betrekkingen. Voor Theo Janssen bij zijn Vijftigste Verjaardag. Stichting Neerlandistiek VU,Amsterdam/ Nodus Publikationen,Münster, pp. 273-281.

Von Fintel, Kai, 2008. What is presupposition accommodation, again? Philosophical Perspectives 22(1), 137-170. 
Appendix: additional afterthought uses of let alone in our corpus sample and gathered from various sources

(1) There is not even a postcard to buy, let alone a stamp. (BNC, 1, ARB, W_Misc) [This example is not easily classifiable as being of the canonical or of the deviant type. Some might argue it's generally easier to buy postcards than stamps. However, others might object that stamps are not particularly harder to come by than postcards, by any standard, since you can typically buy them at post offices, obviously, but also at grocery stores, tobacco shops, local supermarkets, hotels, and so on. It's not clear which view is adopted by the speaker, in this case a travel journalist writing about Mongolia.]

(2) The manager and chairman are such strangers to national television that probably less than 10 per cent of football fans would be able to name them, let alone recognise them. (BNC, 1, CBG, W_newsp_other_sports)

[Given the visual nature of television, one would think that a football manager is more easily recognized than named.]

(3) I just wondered what the Queen would say, let alone the duchess's husband. (BNC, 1, CH6, W_newsp_tabloid)

[This appeared in the tabloid Daily Mirror, which in the summer of 1992 published photographs and stories about the Duchess of York sunbathing topless with an American financial manager at a villa near St Tropez. The context mentions Queen Elizabeth II, who was the Duchess's mother-in-law at the time and who was already dismayed by this affair. This sentence quotes a cameraman, who describes what went on in his mind when he heard a daughter of the Duchess call the man 'Daddy', which the tabloid reckoned would be a further 'heart-breaking blow to the Queen'. It is not clear whether (i) the cameraman wished to say that the duchess's husband would obviously be even more shocked than the Queen or whether (ii) he just wanted to say that he first thought about the Queen's reaction and only then about the duchess's husband's reaction, without any ranking of the degree to which their respective reactions could be imagined.]

(4) Not only couldn't the Cardinals find an efficient, let alone decent, replacement for retired quarterback Kurt Warner, but their defense suffered from losing LB Karlos Dansby and DB Antrel Rolle. (COCA, 2010, NEWS, AssocPress) 
[Most would agree that decent is a weaker term than efficient, so finding (just) a decent player is more likely to happen than finding an efficient player. $\rho^{9}$

(5) One of the guitarists in our band, to his full credit, averages five hours a day practice on the guitar. For me on the drums, I'm pleased if I make it to four, let alone three. (http://www.drummerworld.com/forums/showthread.php?t=69876)

(6) And I miss having friends, let alone one friend right now. (http://www.reddit.com/r/relationship_advice/comments/19ja3f/tell_me_29f_im_not_al one/)

(7) I don't have a gf that squirts. Let alone a gf. (http://www.reddit.com/r/reactiongifs/comments/123j5n/mfw_i_dont_have_a_gf_that_ squirts_let_alone_a_gf/)

[our apologies for the racy nature of this example - XXauthor initialsXX]

(8) Didn't expect to like let alone play this but I do! (http://www.metafilter.com/129077/the-fire-is-dead-the-room-is-cold)

(9) Glenn Haussman, executive editor of industry publication Hotellnteractive.com, says deciding how to modernize the in-room entertainment system has been a vexing challenge for hotels. "Figuring out precisely where consumer desires will be in five years is tough, let alone six months from now," he says.

(http://www.greenvilleonline.com/article/20130702/BUSINESS/307020005/Hotelsupgrade-more-interactive-TVs)

(10) I would never date a guy who wore full on makeup, let alone tinted moisturizer. (http://intothegloss.com/2013/03/harry-brant-student/)

(11) Most people get scared simply hearing the term Mutual Fund, let alone any other financial jargon.

(https://www.amfiindia.com/new-to-mutual-funds/what-are-mutual-funds)

(12) Cleveland... was a constantly-whining ... annoying load, who was kind of hard to love, let alone just even like.

(http://blogs.indiewire.com/shadowandact/is-the-cleveland-show-headed-forcancellationville)

${ }^{9}$ As pointed out by David Denison (personal communication), this sentence may in fact be an instance of the canonical type, since decent could mean, via conventional understatement not just 'satisfactory' but in fact 'pretty good'. In that case, finding a decent player is harder to accomplish than finding a (merely) efficient one. 
(13) "Major League Baseball's non-waiver trade deadline can bring grown men to tears, let alone sleepless nights, and that's just from the constant barrage of emails and texts from reporters trying to ascertain the trade picture."

(http://www.usatoday.com/story/sports/2013/06/30/trade-talks-cubs-white-soxbrewers-phillies-giants-ricky-nolasco-matt-garza-paul-konerko/2477971/)

(14) "Coming off a season where he was one of the more reliable receivers on the field, let alone in the red zone, Chandler was able to tie both Metzalaars and Riemersma for the most TDs by a Buffalo Bills TE in a season and he didn't play the entire season."

(http://cowboyszone.com/threads/machota-romo-changed-play-on-3rd-and-goalplay-dez-didnt-know.265962/page-6)

(15) "The day before that, Hannity said on his radio show that the judge should dismiss manslaughter, let alone the second-degree murder charges." (http://www.salon.com/2013/07/01/right_wing_media_adopts_george_zimmerman/)

(16) The more competitive the Internet becomes, the narrower your focus should be. And the more specialized your online business becomes, the more visitors let alone the more pre-qualified, loyal, long-term prospective customers your site will receive. (http://www.4hb.com/0520sdhitsclicksvisits.html)

(17) First of all, the Internet is a truly wonderful thing, let alone the fact that you can look at naked women while sending an e-mail to your boss while sitting on the toilet. That in itself is worthy of a gold star. What l'm referring to, though, is the ability to do all your grocery shopping without ever leaving the house.

(http://www.epicmealtime.com/2013/04/01/food-services-of-the-future/) [Note the unequal grammatical function of the conjuncts - B.C., E.D. and V.T.]

(18) My choices for my ten favorite films of all time; my word, what a daunting task this was. Choosing ten favorite films is akin to choosing my ten favorite children (okay, so I don't have ten children, let alone one, but you get the point of the pathetic analogy). (www; URL no longer recoverable; example retrieved in January 2013 )

(19) Also I will be moving soon, and am having a hard enough time finding a place that will allow dogs and cats, let alone just a dog. (www; URL no longer recoverable; example retrieved late 2013 or early 2014)

(20) Dana White says, "it's one of the nastiest knockouts I've ever seen in the fight business, let alone on the Ultimate Fighter." (http://www.buddhasport.com/mma/external-video/2013-02-06/uriah-halls-ko-fromthe-ultimate-fighter; quoted from spoken commentary) 
(21) Last time I checked, human cloning was illegal, let alone impossible.

(TV show “Orphan Black," season 1 ep 3 time stamp 00:05:58,891 $\rightarrow$ 00:06:01,892)

(22) Without slaves, they would not have had a kingdom, let alone even a whiff of the good life. They would have survived - just - in conditions of relative poverty, as most desert dwellers have done before and since. (Keys, David. 2004. Kingdom of the Sands, Archaeology 57 (2))

(23) In 2004, the total cost of all robberies in the United States was $\$ 525$ million, and the average loss from a single robbery was about $\$ 1,300$. These amounts are not very high, when we consider how much police, judicial, and corrections muscle is put into the capture and confinement of robbers-let alone the amount of newspaper and television coverage these kinds of crimes elicit. (Ariely, Dan. 2009. Predictably Irrational. New York: Harper Perennial, p. 195) 